\title{
ROMANIZACIÓN Y SINCRETISMO RELIGIOSO EN EL SANTUARIO DE LAS ATALAYUELAS (FUERTE DEL REY - TORREDELCAMPO, JAÉN)
}

\author{
POR \\ CARMEN RUEDA GALÁN \\ MANUEL MOLINOS MOLINOS \\ ARTURO RUIZ RODRÍGUEZ \\ LAURA WIÑA GARCERÁN \\ Centro Andaluz de Arqueología Ibérica \\ Universidad de Jaén
}

\section{RESUMEN}

El hallazgo fortuito de un santuario ibero-romano en el entorno del asentamiento de Las Atalayuelas en (Fuerte del Rey-Torredelcampo, Jaén) ha puesto de manifiesto la existencia de un modelo de culto vinculado al proceso de romanización, presente en las campiñas jiennense y cordobesa. El santuario se caracteriza por la identificación de dos espacios, uno de los cuales funcionaría como lugar de depósito de un gran conjunto de ofrendas, entre las que destacan pequeños vasos, esculturas en piedra caliza, exvotos de hierro y un pequeño conjunto de elementos de adorno personal.

\section{SUMMARY}

In the year 2000, the Iberian-Roman sanctuary near the settlement of Atalayuelas (Fuerte del Rey-Torredelcampo, Jaén) was discovered by accident. This sanctuary has done necessary the revision of the theories about the cult in the countryside of Jaén and Cordoba. It is characteized by two areas, one of them would be a offering place containing vessels, limestone sculptures, iron exvotes and some personal ornaments.

PALABRAS CLAVE: Exvotos , exvotos de hierro, romanización, sincretismo religioso, Alta Andalucía, Cultura Ibérica.

KEY WORDS: Votive figures, iron votive figures, religious syncretism, Alta Andalucía, Iberian culture.

\section{INTRODUCCIÓN}

El objetivo de este trabajo es el de exponer los avances en el estudio de un santuario ibero-romano, localizado en el entorno inmediato del oppidum de las Atalayuelas (Jaén) (fig. 1), encuadrado de forma general en un marco cronológico comprendido entre el siglo II a.n.e. hasta época augustea, sin poder precisar aún más concisamente el momento inicial, con los datos de los que se dispone actualmente. El oppidum de Las Atalayuelas arranca desde el Ibérico Antiguo, etapa en la que se configura como un centro que participa en el modelo polinuclear definido en la Campiña de Jaén y que ha podido ser constatado en otros sitios similares, como Puente Tablas o
Cerro Villargordo (Ruiz y Molinos, 1993). En esta época el asentamiento se dispone en los Cerros del Morrón y Talayas; muestra de ello es la muralla ibérica que, con una anchura de entre cinco y siete metros, bordea ambas unidades geográficas (Castro et al., 1990). Al oeste de esta zona, separado de este primer núcleo y destacando sobre el conjunto, se ubica el Cerro de las Norias donde también se documentó otro recinto amurallado de esta época (Castro, Ined.). La ocupación de Las Atalayuelas será continua hasta época romana, momento en el que se produce una concentración del poblamiento en la zona central, configurándose una ciudad romana, casi con toda seguridad un municipio, que ocuparía entre unas 5 y 7 has (Castro, Ined.). Durante la llamada crisis del siglo II a.n.e. este lugar sería abandonado aunque se han documentado evidencias de época bajoimperial que quizás indiquen algún tipo de ocupación marginal del sitio (Castro, inéd.).

\section{LOS ESPACIOS DEL SANTUARIO}

Antes de entrar en la descripción de los distintos espacios del santuario sería necesario exponer las causas de la intervención, que en definitiva influyeron en la metodología aplicada y en los resultados obtenidos de la misma.

Esta actuación arqueológica se realizó con el objetivo de evaluar los daños producidos por un fuerte expolio que ya indicaba la excepcionalidad del sitio. Los trabajos de excavación lograron clarificar que se trataba de un santuario periurbano, localizado en la ladera sur del denominado Cerro de las Norias, unidad geográfica cuya posición y configuración topográfica lo convierten en la zona más dominante del conjunto de Las Atalayuelas, aunque en desuso en el momento de funcionamiento de este centro de culto (Castro et al., 1990). Esta localización podría indicar la posibilidad de aprovechamiento de materiales 


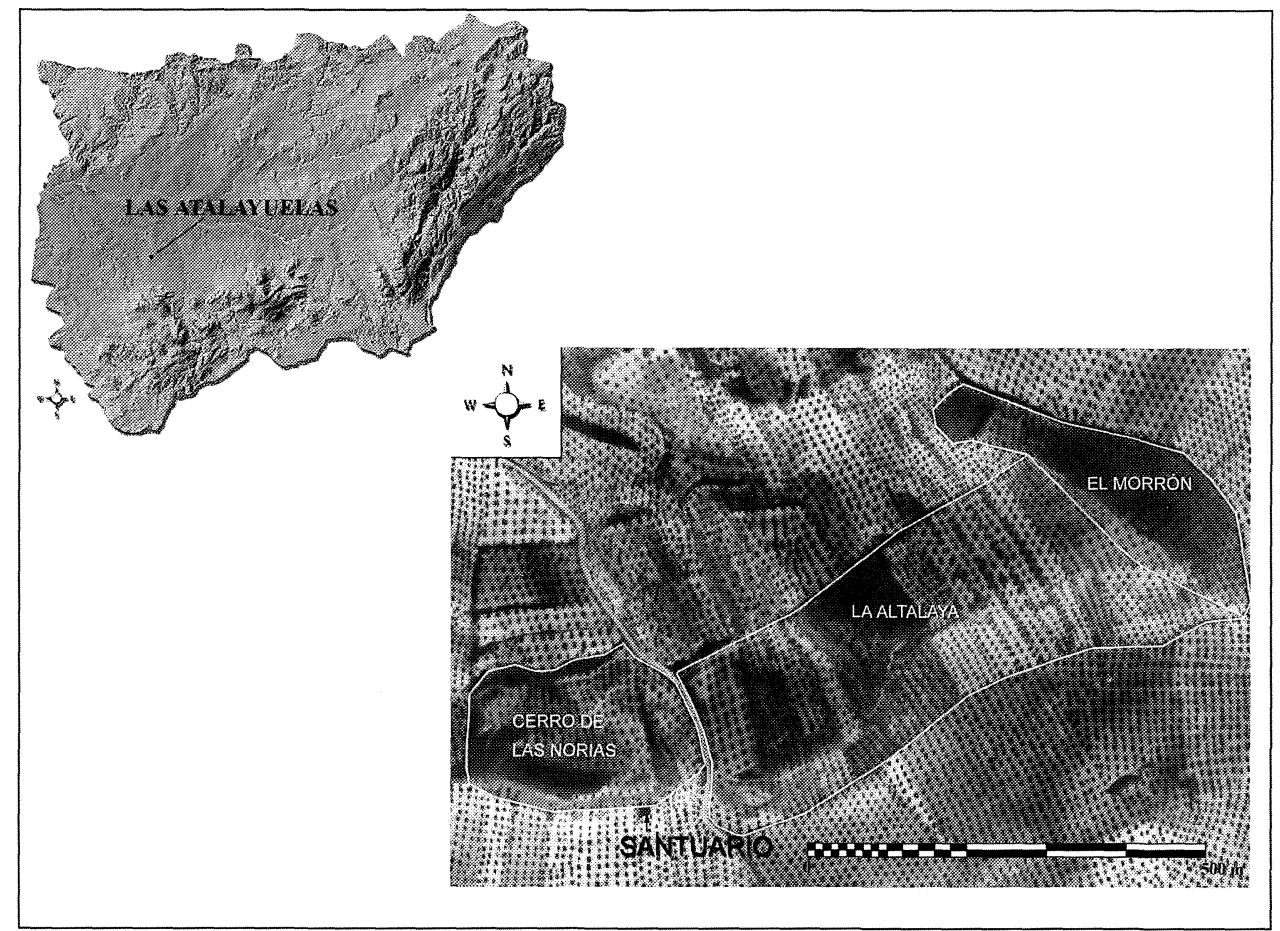

Fig. 1. Localización del asentamiento de Las Atalayuelas en la Provincia de Jaén y su ubicación en el asentamiento. Plano base: Instituto Cartográfico de Andalucía MTN 925 P-5 Nº19. Septiembre 1996. Escala 1/5.000.

pertenecientes a la ocupación anterior, así como, desde el punto de vista estructural, funcional y simbólico, la posible relación física entre el santuario y la muralla ibérica que bordea todo el Cerro de las Norias, fechada hacia el siglo VI a.n.e. (Castro et al., 1990), hecho que deberá ser comprobado en posteriores intervenciones.

El santuario, con orientación Norte-Noroeste/ Sur-Sureste, está dispuesto sobre una ladera. Para salvar el desnivel natural de la misma fue precisa la modificación del terreno original con el fin de nivelar regularmente la zona tal y como se ha documentado, aunque con diferencias espaciales y temporales, en otros santuarios, como Collado de los Jardines (Rueda, inéd.), La Cueva de la Lobera (Nicolini et al., 2004) o el Pajarillo (Molinos et al., 1998). De esta forma en los santuarios antes citados de Despeñaperros, Castellar y Huelma, la ladera donde se asientan es aterrazada con el fin de disponer distintas estructuras que siguen un diseño predeterminado: la configuración de un marco adecuado de monumentalización desde posiciones escenográficas que permiten una adecuada visualización del sitio e incluso una jerarquización de los espacios (Rueda, inéd.).

En el santuario de Las Atalayuelas la estructuración se consigue gracias a la creación de un sistema de aterrazamientos consistente en el relleno por medio de una potente capa de sedimento fino muy compactado, sobre el que se construye un suelo de tierra batida. Este sistema de aterrazamientos, muy bien documentado en la zona sur (Espacio B), se apoya directamente en los muros perimetrales de cada espacio, de modo que éstos sirven a su vez como muros de contención de las presiones generadas por la propia edificación. Se construyen al menos tres terrazas, dos de las cuales se corresponden con las estancias documentadas, aunque si atendemos a paralelismos con el santuario de Torreparedones y al análisis topográfico, podría existir una terraza más, probablemente correspondiente al nivel superior.

Esta articulación de terrazas elimina de forma clara el desnivel natural de la ladera, aunque todavía la diferencia de cota entre los dos niveles generados obliga a la creación de un sistema de escalones para el acceso de un espacio a otro. En este caso, dichos escalones coincidirían con la puerta que da entrada al espacio localizado al norte (Espacio A). Este hecho queda avalado por la presencia de un dintel con rebaje para encajar el gozne y de un conjunto de clavos y grapas de hierro documentados en esta zona, que formaban parte de la estructura de madera de la puerta. A todo esto hay que añadir el hallazgo de 


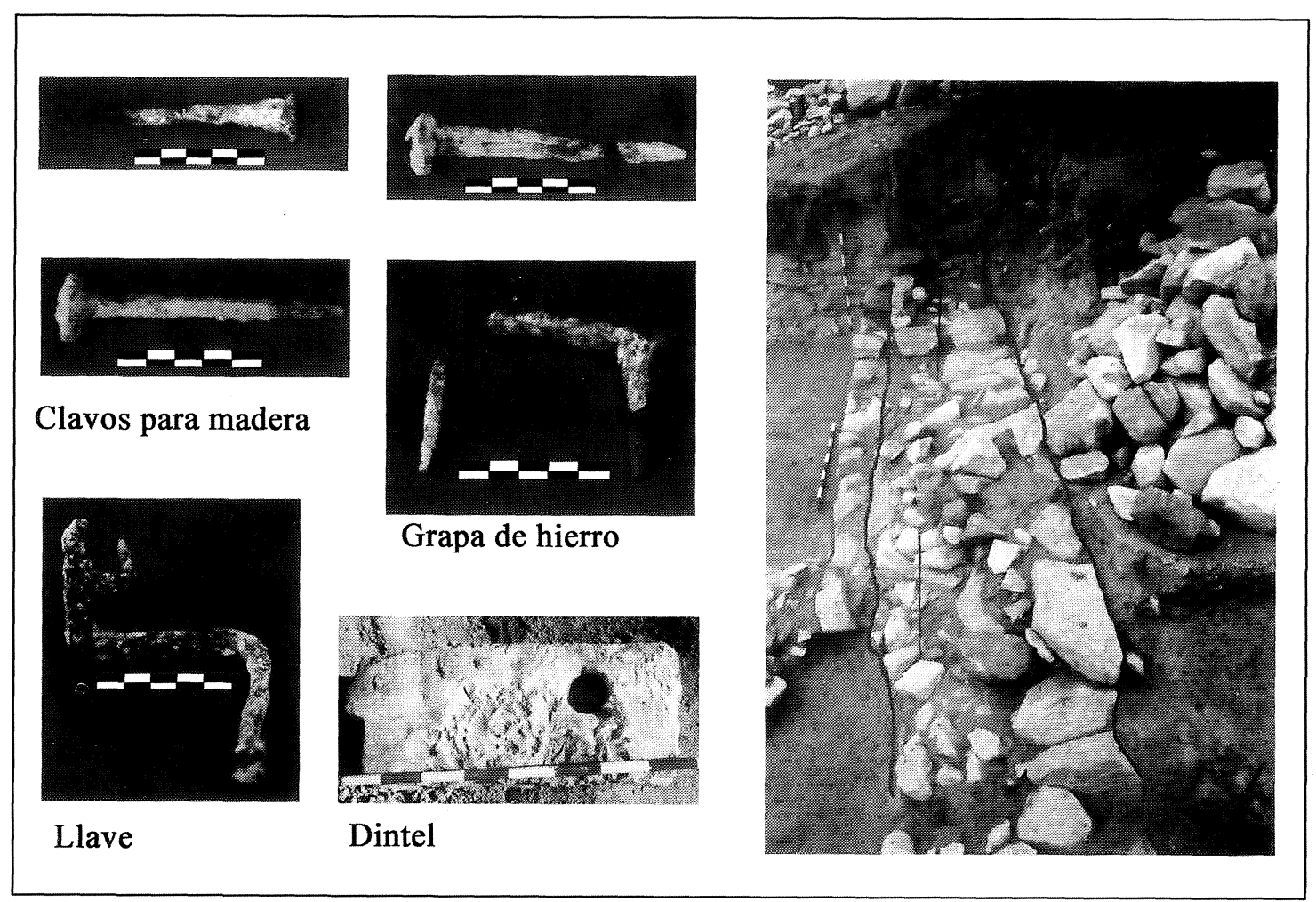

Fig. 2. Detalle del muro medianero de los Espacios A y B del santuario con indicación de los materiales asociados a la puerta que comunica ambos espacios.

una llave de hierro de la época, que podría pertenecer al cierre de la misma (fig. 2).

Aún se desconoce la estructura completa del santuario debido al actual estado, aún parcial, de la excavación, por lo que es arriesgado pretender precisar sus dimensiones reales. La longitud total excavada del edificio, con dirección Norte-Noroeste - SurSureste es de doce metros, mientras que su anchura mínima comprobada es de seis metros.

Como se ha dicho anteriormente, la excavación ha permitido la documentación de dos espacios con características estructurales y funcionales bien diferenciadas, que han sido denominados «Espacio A» (localizada más al norte, a escasos 20 metros de la fortificación) y «Espacio $\mathrm{B} »$ (correspondiente a la segunda terraza) (fig. 3).

\section{ESPACIO A}

Es un área en la que se han documentado dos fases de ocupación, hecho avalado por el hallazgo de dos pavimentos a distintos niveles, entre los que aún no se ha podido precisar la diferencia cronológica, aunque todos los indicadores parecen revelar un lapsus temporal corto.

El pavimento inferior se encuentra sellado por un relleno de tierra y restos cerámicos, unidad que es nivelada y sobre la que se dispone el pavimento más reciente. A esta fase se asocia un muro con orientación Norte-Sur que igualmente queda sellado por dicho pavimento más reciente.

Bajo el pavimento más antiguo se documentó un nivel deposicional de ceniza muy homogéneo y compacto, de unos $20 \mathrm{~cm}$ de espesor, que puede ser interpretado como un nivel de incendio, quizás vinculado a determinados ritos de purificación y fundación del santuario, tal y como se ha documentado en otros centros de culto, como es el caso del santuario de El Pajarillo en Huelma (Molinos et al., 1998). Los análisis antracológicos ${ }^{1}$ realizados indican la presencia de lentisco y retama, dos especies arbustivas muy adecuadas para la combustión, además de ser dos variedades características por sus propiedades aromáticas.

\footnotetext{
' Los análisis están siendo desarrollados por la Dra. Maria Oliva Rodríguez Ariza, del Centro Andaluz de Arqueología
} Ibérica. 


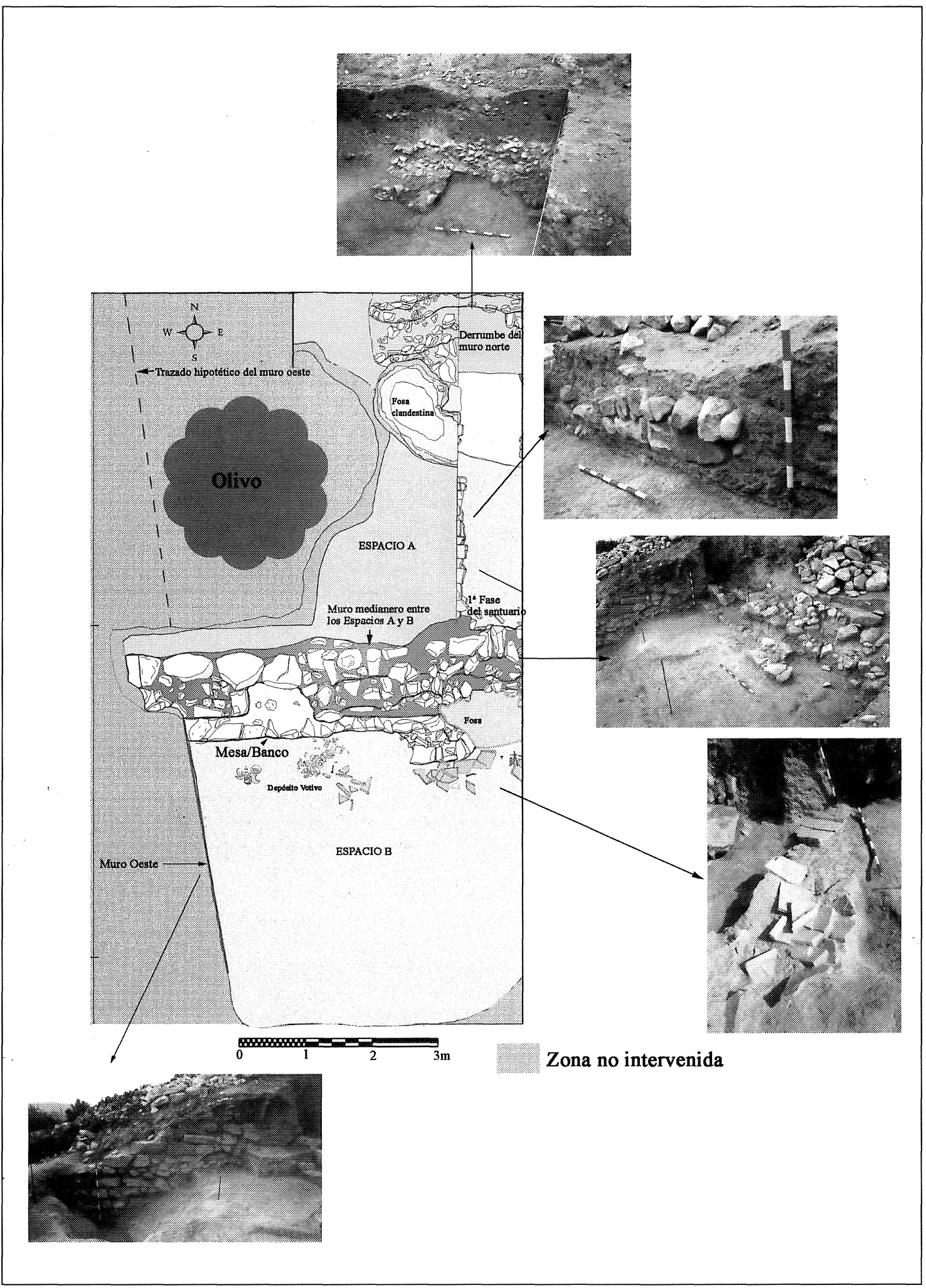

Fig. 3. Planta general del santuario con la indicación de los espacios y estructuras excavadas. 


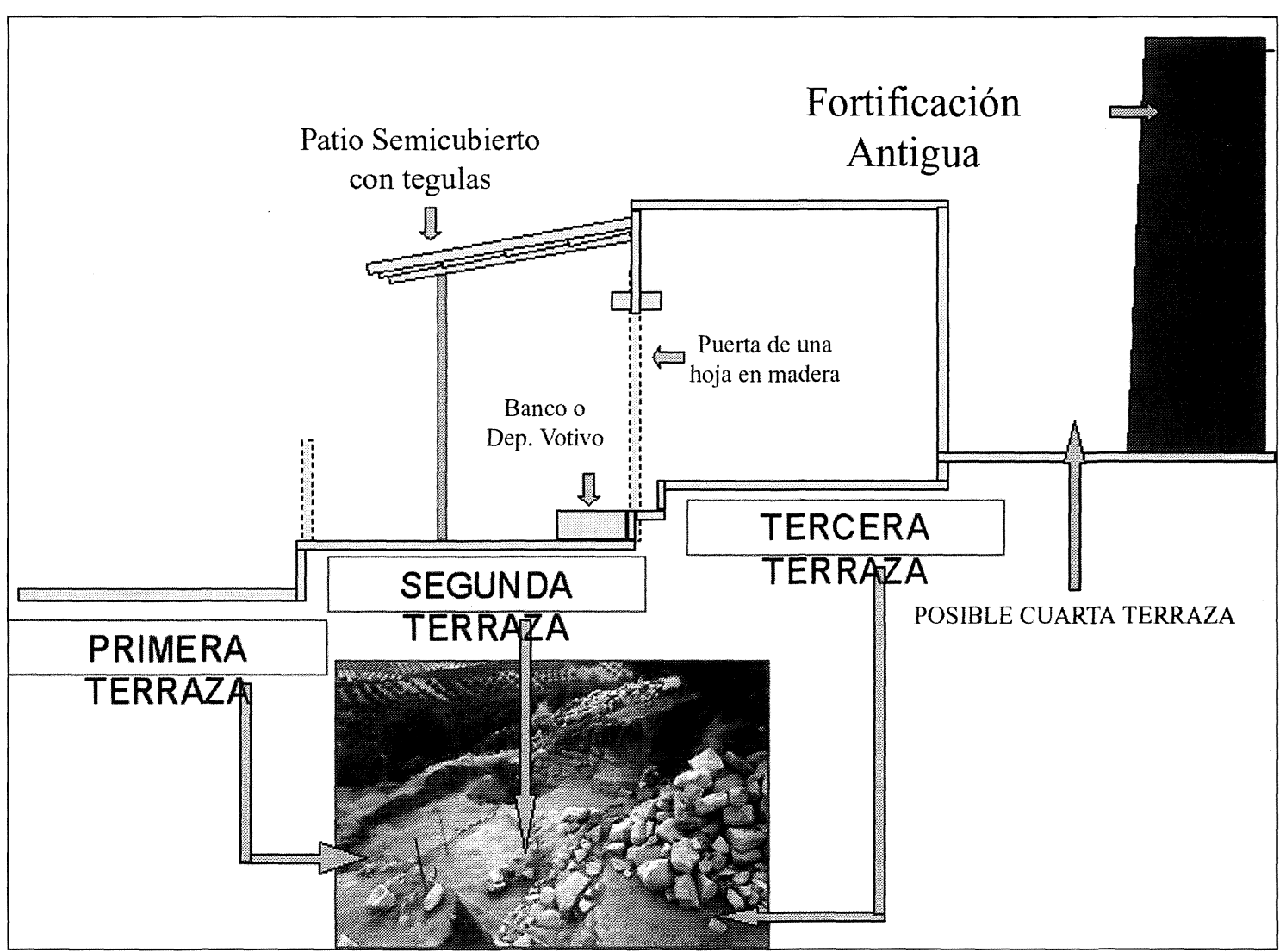

Fig. 4. Reconstrucción esquemática del perfil del santuario.

Tampoco se pueden establecer las dimensiones de este espacio para su segunda fase de ocupación, únicamente se ha documentado el muro de cierre al sur, del que se conserva un alzado medio de $55 \mathrm{~cm}$. Uno de los aspectos más interesantes revelados por la excavación ha sido la notable diferencia existente entre los distintos contextos arqueológicos documentados. De este modo, no se han localizado materiales asociados a la segunda fase de ocupación de este espacio y los documentados sobre el primer pavimento pueden ser interpretados como parte del relleno efectuado para la consecución del segundo. Como se verá más adelante, este hecho contrasta claramente con la situación del Espacio B en el que, por el contrario, se ha documentado una gran concentración de materiales votivos, lo cual permite interpretarlo como el lugar de depósito de las ofrendas del santuario en su última fase.

\section{ESPACIO B}

Localizado al sur, se trata de un espacio donde sólo se ha comprobado una fase de ocupación, la correspondiente a la etapa más reciente, no obstante, no se puede descartar la posibilidad de que funcionase también durante la primera fase, localizada en el Espacio $\mathrm{A}$, puesto que así parece indicarlo la homogeneidad del diseño estructural del complejo de culto.

Tampoco se conoce la disposición total de su configuración estructural. La excavación realizada permite establecer la existencia de una anchura mínima (Este-Oeste) de $5 \mathrm{~m}$ y una longitud (NorteNoroeste/Sur-Sureste) de $6 \mathrm{~m}$. Se han documentado sus muros perimetrales en el lado oeste, formado por mampostería de gran tamaño dispuesta de forma irregular, adaptado a la pendiente natural de la ladera; y norte, de similares características constructivas, separador de los espacios A y B, en el que, como se ha dicho anteriormente, se localiza la puerta de acceso al Espacio B (fig. 4). A este muro se adosa, en su lado oeste, un pequeño banco en el que estaban ubicadas las ofrendas.

Este conjunto votivo (fig. 5), que se describirá más adelante, está integrado por varios tipos de materiales: cerámica, monedas, alfileres, exvotos de piedra y hierro, agujas de hierro, un vasito de plata, un cuenco de bronce, fragmentos de vidrio, cuentas de collar y posiblemente armas, ya que entre los res- 


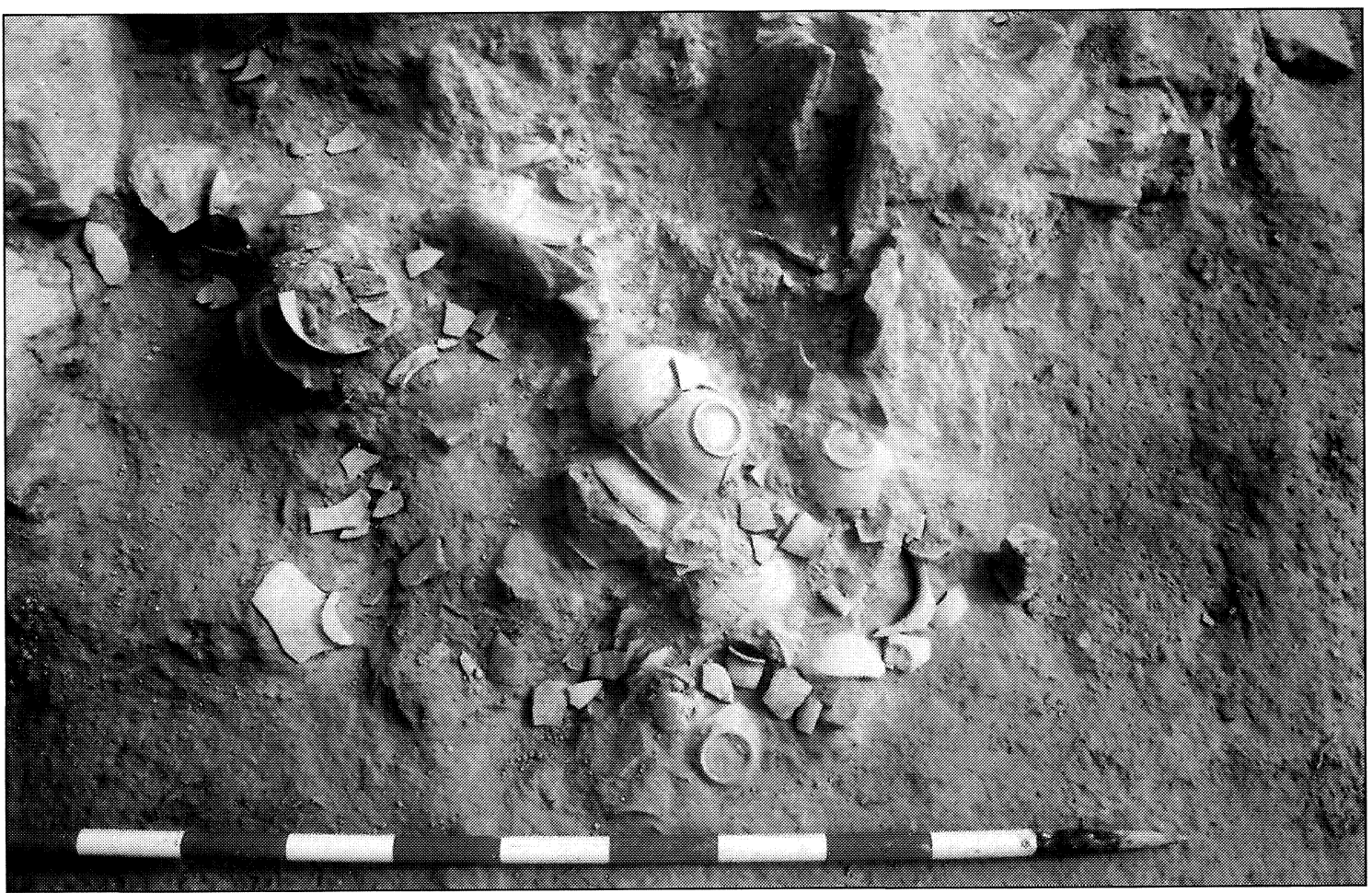

Fig. 5. Detalle de parte del conjunto votivo en el momento de su excavación arqueológica.

tos desechados por los expoliadores se localizaron restos de una espada corta. También es destacable la presencia de restos de fauna, que en este momento son objeto de análisis.

Se trata de un conjunto muy amplio y bastante numeroso de objetos que, sin duda, otorga a este espacio el carácter de contenedor de ofrendas, es decir de thesaurus: un espacio semicubierto, en este caso por una techumbre de tegulae desplomada directamente sobre el depósito votivo. Derivadas del análisis de ambos espacios se observan claras diferencias de tipo estructural y fundamentalmente de tipo funcional: por una parte, el carácter de depósito de ofrendas del Espacio B, en el que se localizan numerosas donaciones, en contraposición al Espacio $A$, en el que no se ha hallado ningún vestigio votivo o indicadores asociables a la realización de rituales. Este hecho puede reforzarse con la dialéctica estructural de ambos espacios (abierto-cerrado) a lo que habría que añadir la presencia del nivel de incendio ritual o fundacional del Espacio A.

\section{LAS OFRENDAS}

El estudio de las ofrendas asociadas a un determinado espacio sagrado debe entenderse como uno de los trabajos más necesarios en el proceso de investigación del culto practicado en el mismo. Sin duda, las ofrendas son una parte muy importante de la materialización directa de la estructura del hecho religioso practicado en un lugar de culto (Cerrillo, 1990).

En este sentido, son muy interesantes los resultados que pueden obtenerse del análisis de un conjunto votivo como el documentado en el santuario de Las Atalayuelas. Efectivamente, la característica inicial que puede señalarse es su heterogeneidad, hasta tal punto que 'conviven' exvotos de hierro o piedra con elementos de adorno personal, monedas, armas, etc. Otro aspecto es el relativo a la presencia de numerosos elementos cerámicos (la ofrenda más frecuente) que formaron parte de algún tipo de ritual. En este caso, estos vasos se configuran como un objeto sagrado, resultado del ritual del que formaron parte. Esta variedad de elementos hace necesario el planteamiento de un estudio individualizado y particularizado de cada grupo o categoría de ofrendas, con el objetivo de indagar en la posibilidad de conocer si nos encontramos ante determinados ritos o, al menos, significados religiosos o simbólicos comunes, integrantes de una misma estructura ideológica.

De cualquier modo, el contexto arqueológico responde a un fenómeno religioso generalizado en la 
práctica litúrgica ibérica: el constante diálogo establecido entre el practicante/oferente y la divinidad para la solicitud o agradecimiento de necesidades de orden primario (fertilidad, cosechas, enfermedades,...) (Morena, 1997; Ruiz, 1983). El mecanismo responde al establecimiento de una relación directa entre el oferente y la divinidad, una relación contractual con un marcado carácter de reciprocidad en la que no existen intermediarios, en la que el practicante pide la realización de un favor y lo agradece mediante una promesa o recompensa en caso de ser beneficiado (Blázquez et al., 1993). En el acto de la petición del favor o en el acto del agradecimiento por la concesión del mismo el oferente porta el exvoto que, en un sentido muy amplio, debe ser entendido como la materialización de la interrelación personal con la divinidad. En ambos casos, este mecanismo presupone un marcado carácter público del exvoto puesto que el mismo se convierte en un espejo de la condición benefactora de la divinidad que además refuerza los vínculos identitarios de una determinada colectividad. Por tanto, el exvoto formaría parte de todo un sistema de códigos que son entendidos en su significado simbólico a nivel social (Olmos, 1992a), códigos que condicionan la imagen definitiva proyectada del oferente y de su acción de súplica (Cobos y Luque, 1990). De este modo, en algunos casos, el exvoto es una idealización muy compleja del oferente y la súplica, mientras que en otros se tiende a la simplificación de ambos, por ejemplo, representando partes del cuerpo que simbolizan algún tipo de dolencia. En cualquier caso, la representación de la figura del oferente, de su cuerpo, de sus gestos o de ciertas características directamente relacionadas con la persona que ofrenda debe entenderse como una entrega simbólica de lo más valioso que tiene el propio devoto: su persona (Olmos, 1992a).

Todas estas características tienen un claro reflejo en el conjunto votivo del santuario de Las Atalayuelas, ya que aunque existen determinadas diferencias, las ofrendas depositadas en su thesaurus poseen un claro carácter de exvoto, de donación permanente en el sitio.

\section{EXVOTOS EN HIERRO ${ }^{2}$}

Entre los materiales localizados en dicho thesaurus destacan dos exvotos de hierro (fig. 6) que constituyen dos piezas únicas en su repertorio, debido a

${ }^{2}$ Agradecemos a Ricardo Olmos (Instituto de Historia, CSIC, Madrid) sus comentarios y sugerencias. su propia materia prima, el hierro, alejado de la plástica del bronce, facilitada por la técnica de fundición en molde a cera perdida, frente a la rigidez que presenta la transformación del hierro a través de su forjado y martilleado; y debido también a su estilo, aunque sin duda reflejan las tradiciones estilísticas de sus predecesores, como la hipertrofia de las manos en relación al resto del cuerpo, sus palmas abiertas frontalmente o la representación del sexo a través de la exageración de las caderas, aspectos que vuelven a conectar con ritos de propiciación de fecundidad y/o fertilidad.

Ambas piezas representan figuras humanas desnudas (una masculina y otra femenina), de dimensiones muy similares (entre 10 y $12 \mathrm{~cm}$ ). El diseño es muy particular destacando su frontalidad, como eje de observación; los brazos se muestran extendidos, abiertos, formando un ángulo recto respecto al eje del cuerpo; los pies se han conseguido mediante la torsión y el martilleado de los extremos de las piernas y los ojos, muy mal conservados, quedan marcados por medio de dos pequeños circulitos cincelados.

Como se observa, de forma general recogen aspectos muy presentes en la gestualidad y atributos de los exvotos de bronce de otros santuarios de la Alta Andalucía, no obstante, es necesario resaltar un aspecto probablemente cargado de significado en el contexto de este santuario: la presencia de ambos sexos dentro de un mismo esquema plástico que, probablemente, esta representando a una misma pareja de exvotos, esto es, de oferentes. La diferenciación de sexos queda implícita mediante la representación del desnudo de ambas piezas. En el caso del exvoto masculino, el falo no aparece hipertrofiado, aunque sí destacado, mientras que la mujer es representada a través del resaltamiento de las caderas y la zona pélvica. El resto de la composición es similar, no pudiéndose observar ninguna otra diferencia atributiva o anatómica. En suma, puede indicarse que ambos exvotos fueron concebidos bajo un mismo esquema técnico e iconográfico: ambos se muestran ante la divinidad en igualdad de condiciones. Este esquema de representación puede seguirse en los bronces ibéricos, más concretamente en el tipo reconocido como orante desnudo, tipo que se representa con los antebrazos levantados, las manos abiertas y sus palmas al frente (Álvarez Osorio, 1941, Lám. CXX y LXVIII; Nicolini, 1969, Lám XXXII; Nicolini, 1977, n46-47; Prados, 1992, n $112,113,1159,1160)$.

\section{ESCULTURAS EN PIEDRA}

En estrecha relación con los exvotos en hierro, y como partícipes del mismo tipo de culto y práctica, 

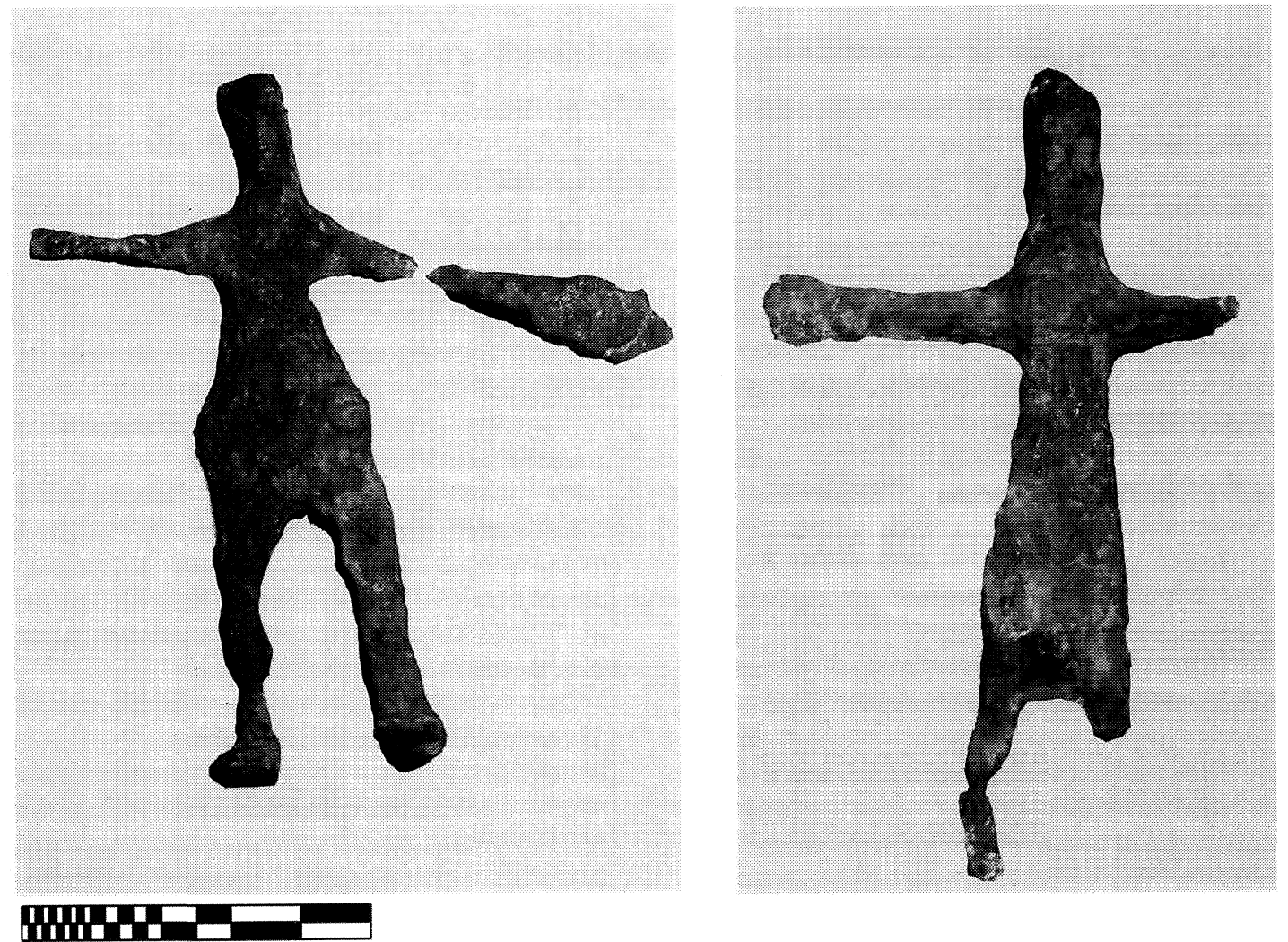

Fig. 6. Exvotos en hierro.

en el santuario de Las Atalayuelas aparecen otra serie de fragmentos de esculturas realizadas en piedra, muchas de las cuales debemos interpretar como ofrendas.

Existe un claro paralelismo funcional y estilístico con los exvotos aparecidos en el Santuario de Torreparedones (Fernández Castro y Cunliffe, 2002, Morena, 1989/1999). Además también pueden correlacionarse con diversos hallazgos aislados procedentes de la provincia de Córdoba que igualmente han sido identificados como elementos cultuales, como en los casos de Montemayor, Ategua, el Cerro de los Molinillos, Torremorana y, probablemente, Espejo (Vaquerizo, 1997; Morena, 1997). Tampoco hay que olvidar las esculturas procedentes de Torrebenzalá (Torredonjimeno) y La Bobadilla (Alcaudete) en la provincia de Jaén (Morena, 1989), que comparten cierta tendencia estilística, como el esquematismo y que han sido identificadas como restos pertenecientes a posibles centros de culto de características similares en un marco geográfico acotado (Ruano, 1987); sin obviar, por último, algunas de las representaciones en piedra procedentes de otros santuarios como el Cerro de los Santos simi- larmente esquemáticas (Ruiz Bremon, 1989) y la Encarnación (Ramallo, 1993).

El conjunto de piezas de estos santuarios han sido consideradas como resultado de una artesanía local y restringida, hasta el punto de que no se han estimado coincidentes con los hallazgos puntuales anteriormente señalados (Fernández Castro y Cunliffe, 2002). En efecto, puede tratarse de talleres locales vinculados a un santuario, aunque existe un hilo conductor, a nivel religioso, que hace coincidir ciertas características no limitadas al ámbito estilístico sino también respecto a su significado cultual. Los recientes hallazgos realizados en Las Atalayuelas son un aval suficiente para trabajar en esta línea de analogías a distintos niveles y escalas, no obstante, nuestro análisis se centrará en los exvotos de piedra.

Se podría decir que la primera característica común en todos ellos es el material y la técnica de fabricación. El material es una caliza blanca, muy blanda, relativamente abundante en las campiñas jiennense y cordobesa, lo que diferencia a estas esculturas de las de los santuarios albaceteño y murciano, fabricadas en arenisca. La caliza facilita el trabajo de cincelado, retocado y pulido. En cuanto a 


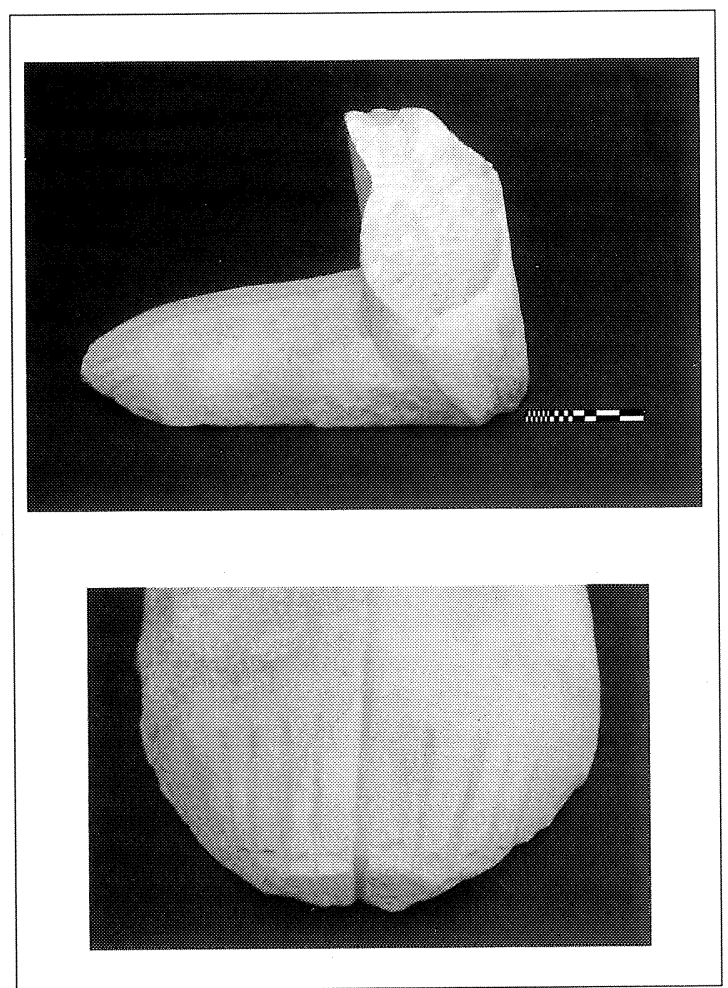

Fig. 7. Fragmento de escultura anatómica en piedra caliza representando unos pies, con el detalle de la representación de los dedos.

las fórmulas de representación de las piezas procedentes de Atalayuelas debemos diferenciar dos grupos: las esculturas en bulto redondo y las placas en bajo o altorrelieve.

Las esculturas en bulto redondo se realizarían por medio de cincelado, rematado mediante buril para al final alisar y pulir el conjunto. Por lo que respecta a las placas el trabajo consistiría en su grabado, mediante incisiones, reducidas en ocasiones a finísimas líneas y trazos. La mayoría de las piezas, tanto las de bulto redondo como las placas, están diseñadas para potenciar un único plano de observación y expresión: el frontal, un rasgo característico generalizado en la mayoría de los exvotos (Olmos, 1992a). La existencia de ambos elementos escultóricos podría indicar su funcionalidad y ubicación en el marco estructural del santuario.

Dentro de los elementos en bulto redondo, todos figurativos, debe señalarse que únicamente se ha documentado un exvoto anatómico, correspondiente a unas piernas desnudas ${ }^{3}$ (fig. 7), que sin duda recuerdan a las documentadas en Torreparedones

${ }^{3}$ Las dimensiones de esta pieza son de 7'90 $\mathrm{cm}$ de altura por $19^{\prime} 40 \mathrm{~cm}$ de anchura.

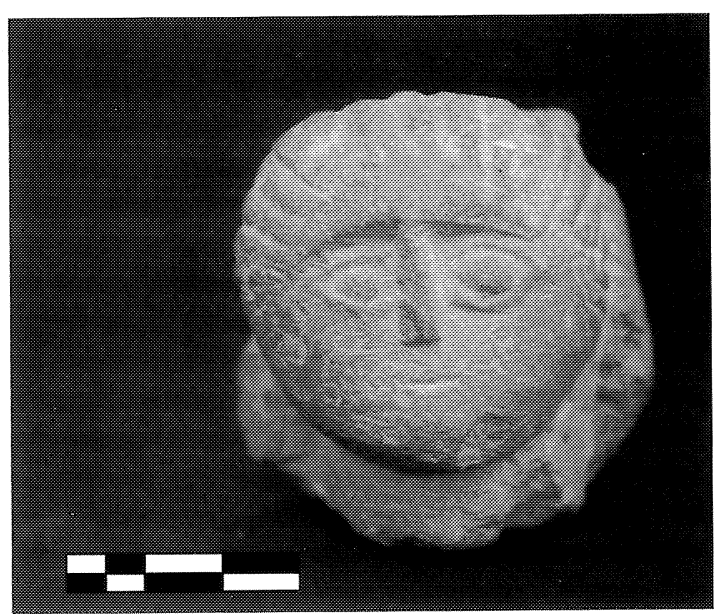

Fig. 8. Fragmento de escultura hallada en el entorno de Las Atalayuelas.

(Morena, 1989) o a la hallada en Ategua (Vaquerizo, 1997; Morena, 1997). Su característica fundamental es la simplicidad de las formas, aunque con un esbozo de naturalismo, aspectos que se ponen de manifiesto en el tratamiento de la representación de los dedos de los pies, con indicación de la uña o en la separación de ambas piernas, realizada a través de una simple incisión o acanaladura continua, que arranca desde el extremo del pie, asciende hasta el final de la pieza y se marca en el lado posterior de la misma. Con respecto a la representación de los pies, cabe señalar la búsqueda de la diferenciación del tamaño de sus falanges, con la clara intención de aproximarse a la realidad anatómica.

Dentro de este grupo de bulto redondo la siguiente categoría es la correspondiente a exvotos figurativos, dentro de la cual se han documentado cuatro piezas, todas muy fragmentadas e incompletas, hecho que sin duda limita las posibilidades de su estudio estilístico e iconográfico.

La primera es un fragmento de $11^{\prime} 40 \mathrm{~cm}$. Consiste en parte del brazo de una figura humana, de la que no se puede precisar el sexo, la cual vestiría un manto cuya caída se representa por medio de líneas entrecruzadas y decoraciones en espiga. Esta pieza se caracteriza por el material, una piedra muy blanca y dura, de difícil modelado.

El segundo fragmento escultórico tiene $10^{\prime} 30 \mathrm{~cm}$ conservados. Es una pieza tosca, esculpida en un bloque macizo que representa a una figura humana sedente con túnica larga, hasta los tobillos, elemento que se insinúa de una forma muy simple, mediante la incisión de líneas entrecruzadas con el fin de idealizar la caída de los pliegues de la misma. A ambos lados de la figura parece sugerirse el arran- 

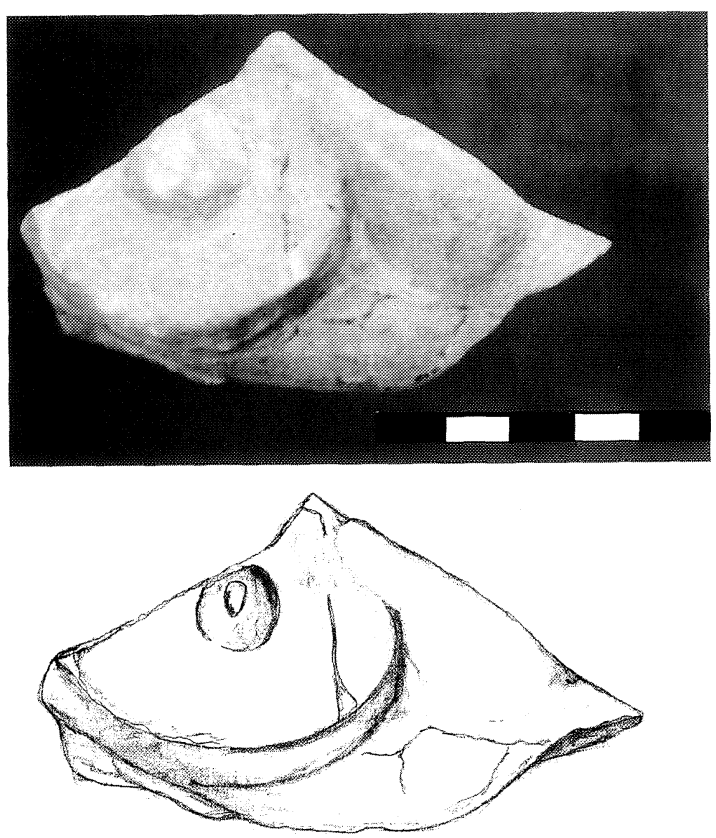

Fig. 9. Fragmento de escultura en piedra caliza que representa parte de una mano que sostiene una pátera procedente del santuario de Las Atalayuelas.

que de ambos brazos pero su estado no permite esclarecer su posición. En conjunto, esta figura fue diseñada para ser expuesta frontalmente, puesto que su lado posterior está bastante descuidado.

Todas estas características, atendiendo igualmente a paralelismos con las esculturas de Torreparedones, parecen conducir con la posible representación de una figura femenina, tal vez una dama sedente, tipo muy repetido en este último santuario (Fernández Castro y Cunliffe, 2002; Morena, 1999), pero igualmente en Las Atalayuelas, tal y como demuestra el hallazgo, a principios del siglo $\mathrm{XX}$, de piezas de similares características en este entorno (Cazabán, 1920).

La tercera pieza, de 5'40 cm de longitud, representa la cabeza de una figura masculina ${ }^{4}$ (fig. 8). Recoge el mismo esquema mostrado en otras piezas documentadas en esta intervención, es decir, la simplicidad en los detalles y las formas. Mediante su manufactura con trazos muy geométricos y rectos se configuran los rasgos de la cara, como los ojos y la nariz, definida a través de un simple triángulo, o la boca realizada con una incisión horizontal. El pelo se confecciona a base de mechones curvos que reco-

${ }^{4}$ Esta pieza procede del entorno del santuario y fue hallada en los años 80 por el Dr. Marcelo Castro, del Centro Andaluz de Arqueología Ibérica, al que desde aquí agradecemos sus comentarios y sugerencias. rren la cabeza de manera más o menos simétrica. De nuevo, es una pieza concebida para ser observada sólo de frente, hecho que queda confirmado al observar que su parte posterior es lisa, y sin ningún tipo de tratamiento.

Por último, cabe destacar un fragmento, de 6,5 $\mathrm{cm}$ de tamaño conservado, que representa parte de una mano derecha que soporta un elemento a modo de ofrenda que podemos identificar como una pátera mesomphalos (fig. 9). Su fragmentación y erosión han supuesto la pérdida de diversos detalles, entre ellos las distintas falanges de las manos que se encontrarían representadas, conservándose en cambio, en perfectas condiciones, el dedo pulgar.

Se trata de una pieza muy interesante puesto que representa una libación de tipo mediterráneo. En el imaginario ibérico en piedra existen representaciones que muestran este tipo de ritual, como el ejemplo los relieves de Torreparedones (Morena, 1989), Osuna (Olmos, 1992b) o las esculturas del Cerro de los Santos (Ruano, 1987; Ruiz Bremón, 1989), pero en todos los casos el vaso de libación es de tipo caliciforme o carenado típicamente ibérico, que conocemos bien por vasos de plata. El paralelo más inmediato de esta pieza se encuentra en los bronces hallados en la acrópolis de Sagunto, fechados hacia el siglo II a.n.e., entre cuyo conjunto se han documentado representaciones de oferentes que portan en su mano derecha, al igual que en Las Atalayuelas, una pátera (Blech, 1989; Olmos, 1992/1999; Izquierdo, 2003). Este tipo de representación es un indicio más de la época iberorromana y de la influencia itálica en el discurso iconográfico del santuario.

Es indudable que la pátera es un elemento cultual utilizado en libaciones, quedaría, no obstante, por definir en qué espacio del santuario se realizaba este ritual y qué tipo de ofrenda líquida se utilizaba en el mismo. Con respecto a la primera cuestión, en estos momentos no existen indicadores arqueológicos suficientes para establecer un espacio determinado en el que se llevaría a cabo dicho ritual, tampoco se puede afirmar que se realizase en el mismo lugar de depósito de ofrendas, ya que no se han documentado estructuras interrelacionadas con el mismo, como un altar de libaciones (Moneo, 2003). Este tipo de ritual normalmente se desarrollaba con vino, aunque también con miel y agua y, en algunas ocasiones, las libaciones se ejecutaban acompañadas de sacrificios de animales (Blázquez et al., 1993). En Las Atalayuelas también aparecen restos de fauna en el thesaurus, aunque aún es pronto para asociarlos a rituales relacionados con un sacrificio.

Con respecto a las placas decorativas, durante la excavación arqueológica se han rescatado tres, a las 

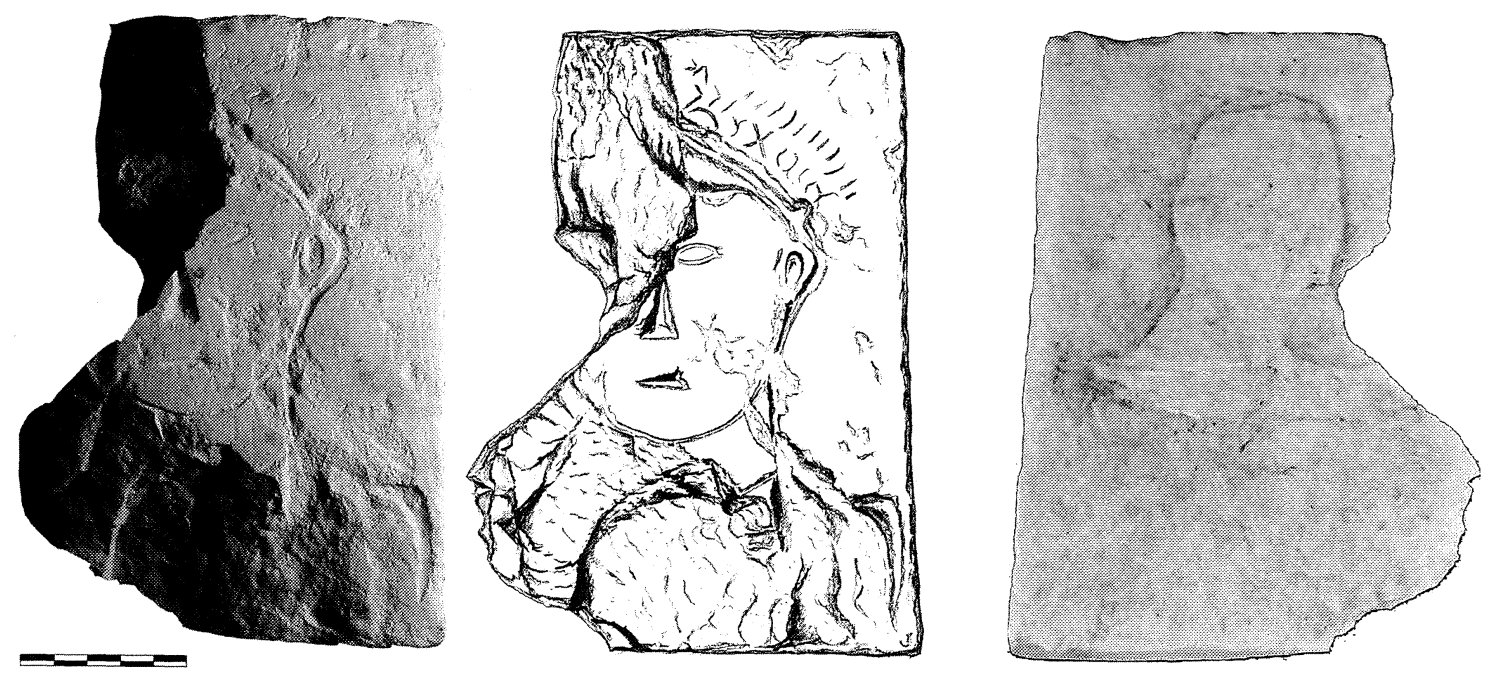

Fig.10. Placa en piedra caliza procedente del santuario que representa una figura masculina. En el reverso el proyecto, abortado, de realización de una imagen en altorrelieve.

que se le une una recogida en las prospecciones superficiales de los años 80 . Todas responden al mismo esquema y temática: son piezas que representan rostros, en su mayoría masculinos, aunque la simplicidad de los rasgos pueden conducir a errores de atribución del sexo. En este tipo de elementos, al igual que en la figura masculina citada, en bulto redondo, se hace hincapié en la representación de los ojos, que aparecen muy abiertos y con la mirada frontal, en actitud de alerta, lo cual es interpretado como un signo de atención a la divinidad por parte del fiel (Olmos, 1992a).

Uno de los ejemplares de mayor interés documentados en el desarrollo de la intervención es una pieza realizada a base de finísimos trazos que representa el rostro de una figura humana, muy probablemente masculina, en la que destaca su hieratismo y detalle ${ }^{5}$ (fig. 10). De esta forma, la boca se representa con una línea recta o la nariz por medio de la forma triangular, con el trazo más pronunciado. Muy original es la forma de ejecutar lo que parece el cabello, por medio de finísimas líneas que serpenteando arrancan radialmente de la cabeza del individuo. La placa está trabajada en todos sus lados por medio de un recorte en ángulo recto. En su lado posterior aparece la huella de la ejecución de un boceto abortado de un individuo en altorrelieve.

Tampoco hay que olvidar que la conocida como «danza bastetana» procede muy probablemente de este santuario (fig. 11). Esta placa ha sido interpretada como una danza ritual (Cazabán, 1920; Alcalá Venceslada, 1930; Ruano, 1982-3; Moneo, 2003) en

\footnotetext{
${ }^{5}$ Sus dimensiones generales son de 18 por $12^{\prime} 80 \mathrm{~cm}$.
}

la que intervienen siete individuos, cuatro hombres $\mathrm{y}$ tres mujeres, agrupados cada sexo en un lado. Otras líneas de investigación hacen una lectura distinta, interpretándola como la plasmación gráfica de una unidad familiar en un momento cronológico en el que el sistema clientelar comienza a transformarse y la familia se convierte en el referente básico de la nueva estructura social representada en estos lugares de culto (Olmos, 1992a).

\section{OFRENDAS CERÁMICAS ${ }^{6}$}

La mayor parte del conjunto votivo hallado en este santuario lo conforman los materiales cerámicos de pequeño tamaño, todos localizados en un espacio acotado y concreto, el correspondiente al murete o banco corrido localizado en el Espacio B, espacio identificado como el thesaurus del santuario. No obstante, habría que determinar qué papel jugaron este tipo de elementos en este contexto sacro, fundamentalmente relacionados con la práctica de algún tipo de ritual, ya que la mayor parte son cuencos ${ }^{7}$ y platos, aunque también se han docu-

\footnotetext{
${ }^{6}$ En la actualidad desde el Centro Andaluz de Arqueología Ibérica se está desarrollando la elaboración de la tipología de los vasos cerámicos del santuario, de modo que este apartado se configura como un avance del estudio más particularizado de este tipo de ofrendas.

${ }^{7}$ En relación a esta forma, la predominante en el depósito votivo, es interesante señalar una figurita en bronce procedente del santuario de Collado de los Jardines y perteneciente a la Colección del Museo Gómez-Moreno, en la actualidad en fase de estudio. Se trata de un exvoto que representa a una oferente masculino que porta, cogido con ambas manos, un
} 


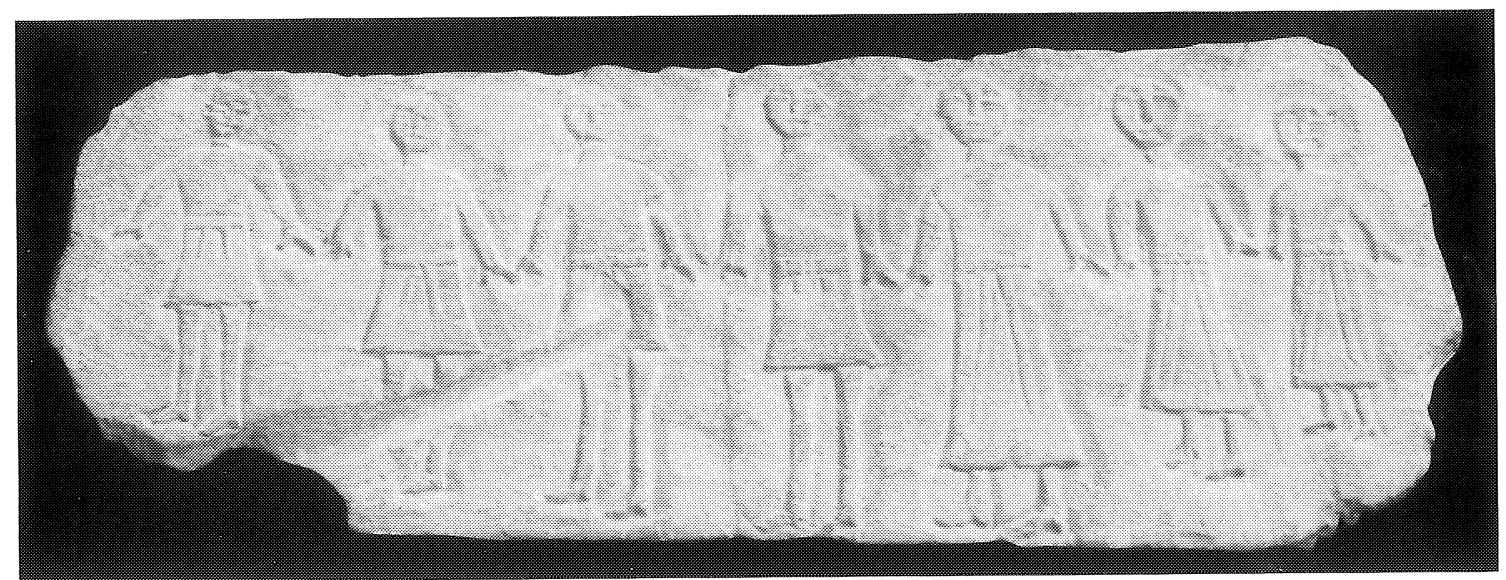

Fig. 11. Relieve de la «Danza Bastetana» (Olmos, 1992).

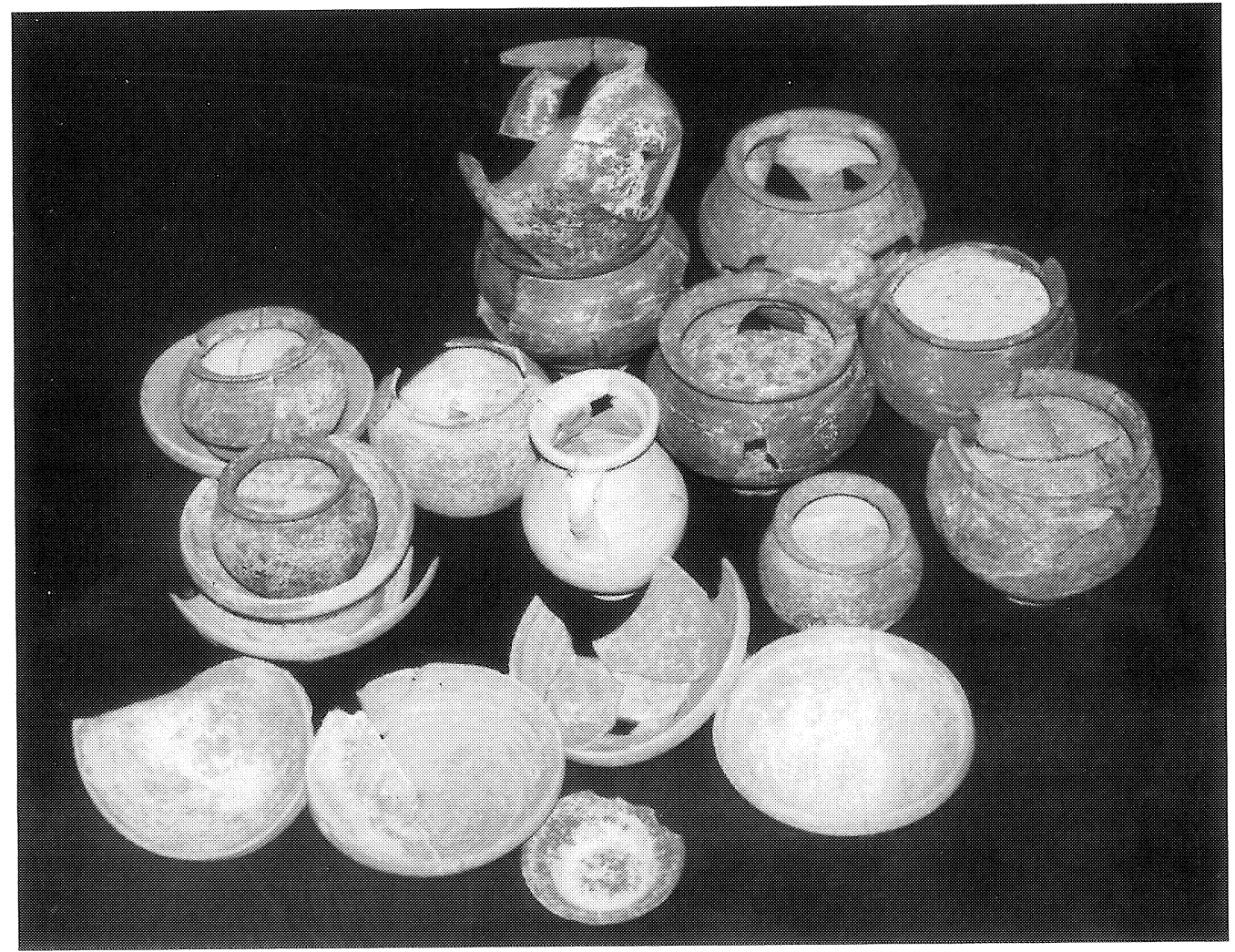

Fig. 12. Recipientes cerámicos procedentes del conjunto votivo de Las Atalayuelas: imagen de varias de las piezas restauradas.

mentado jarras, ollitas y algún vaso caliciforme (fig. 12), elementos normalmente asociados a ritua-

vaso de igual tipología que los documentos por centenares en Atalayuelas. No obstante, no se puede aseverar que este tipo de representaciones se inspiren en el material cerámico, ya que son numerosos los ejemplos de cuencos argénteos procedentes de tesoros peninsulares (Izquierdo, 2003). les de libación (Moneo, 2003), todo ello reforzado por la presencia de un fragmento escultórico que representa dicha acción. Sin embargo, aún quedaría por determinar si las ofrendas no podrían implicar a otro tipo de sustancias como semillas, comida, etc. Se están realizando los análisis de contenido indicados. 

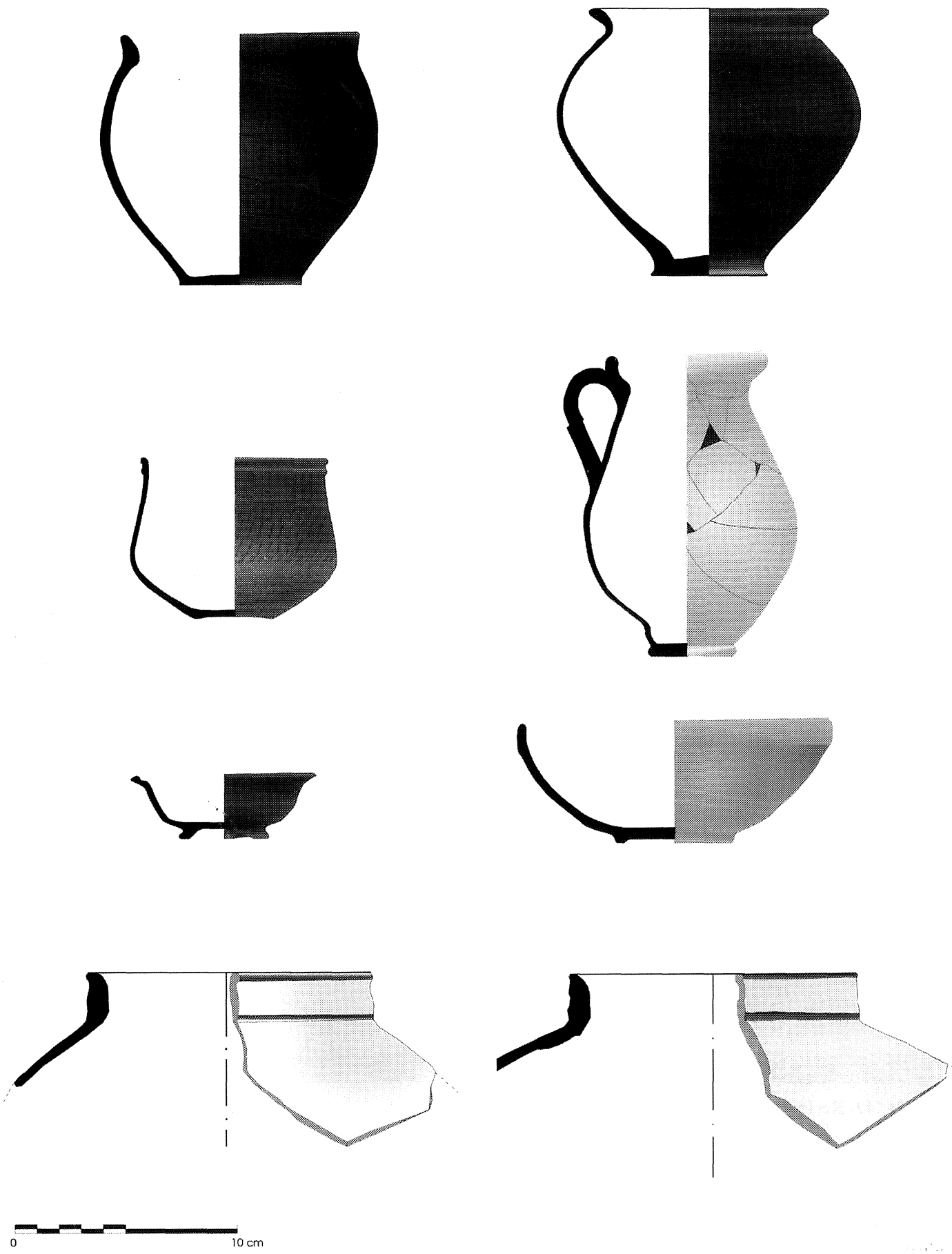

Fig. 13. Dibujo de algunos de los tipos cerámicos identificados. 
Aparte de la problemática de su contenido, la relevancia contextual de estos elementos está vinculada a su entrega irreversible como parte del ritual, puesto que los mismos aparecen apilados, una vez utilizados, en el lugar destinado a esta función. Si los exvotos son la personificación de las demandas/ gratitudes del oferente/practicante, otros elementos, como los vasos cerámicos implicarían la fosilización (no personificada) del ritual mediante su permanencia en el santuario.

Una última característica a resaltar del conjunto votivo de Las Atalayuelas, respecto a la cronología de estos materiales, es el predominio de la cerámica ibérica sobre la romana, aunque se ha documentado alguna pieza de sigillata, varias jarritas de paredes finas, características de esta etapa, y muy probablemente producciones de la primera fase de los Villares de Andújar (Concepción Choclán, comunicación personal) tal y como muestran los primeros resultados del estudio tipológico (fig. 13).

\section{MONEDAS $^{8}$}

En el thesaurus del santuario, formando parte del conjunto de ofrendas, se han documentado dos monedas que suponen un paso importante para la contextualización cronológica del mismo.

La primera es un semis de la $17^{\mathrm{a}}$ emisión, acuñado en la ceca de Carthagonova y ofrece una cronología de principios del siglo I (García-Bellido y Blázquez, 2001: 99). Su estado de conservación impide la identificación de varios de sus elementos, aunque pueden apreciarse los siguientes rasgos: en el anverso, la cuadriga orientada a la derecha y un templo tetrástilo; en el reverso, parte de la leyenda que rodearía al mismo.

La segunda moneda parece pertenecer a la primera de las cuatro emisiones en bronce de la ceca de Orippo, ciudad localizada entre los actuales términos de Coria del Río y Dos Hermanas (Sevilla), con una cronología aproximada comprendida entre de la primera mitad del siglo II a.n.e. y el siglo I a.n.e. (Ripollés y Abascal, 2000; García-Bellido y Blázquez, 2001: 304; Mozas, Ined.). La revisión realizada por la Dra. Ma Paz García-Bellido ha permitido concretar más su cronología, situándola en la primera mitad del siglo II a.n.e.

Esta primera emisión se caracteriza por la representación en el anverso de una cabeza masculina con un racimo de uvas; en el reverso aparece un toro

\footnotetext{
${ }^{8}$ Desde estas líneas queremos agradecer la ayuda prestada por la Dra. $\mathrm{M}^{\mathrm{a}} \mathrm{Paz}$ García-Bellido (CSIC, Madrid) y por Dña. Santos Mozas.
}

arrodillado con el creciente lunar encima y dos letras, A o B, de significado desconocido; bajo él, la leyenda ORIPENSE.

Para completar el estudio numismático, hay que añadir una moneda localizada en el olivar donde se ubica el santuario superficialmente. Fue acuñada en la ceca de Cástulo, donde se realizaron diez emisiones que abarcan una cronología comprendida entre el 220-206 a.n.e. al 80-45 a.n.e. (García-Bellido, 1992; Ripollés y Abascal, 2000: 127; García Bellido y Blázquez, 2001: 228; Mozas, inéd.). Se trata de un semis de la tercera emisión de esta ceca, con una cronología situada entre 195-179 a.n.e. En el anverso aparece una cabeza masculina diademada; en el reverso, un toro mirando a derecha; encima el creciente, y en exergo una inscripción: ka.ś.ti.l.o.

Un aspecto interesante alejado de la mera descripción formal es la interpretación de estos materiales en el contexto del depósito votivo, su significación religiosa y simbólica. No es excepcional la presencia de este tipo de materiales y su documentación vinculada al culto en santuarios, así contamos con varios ejemplos en el Collado de los Jardines o la Serreta de Alcoy (González, 2002). Aunque su presencia puede deberse a distintas situaciones en el caso del Santuario de Las Atalayuelas el contexto arqueológico es claro, no tratándose, por tanto, de una pérdida casual o no interviniendo en un circuito de intercambio sino como elemento con un marcado carácter simbólico, con el estatus de exvoto, al que se añade la apreciación de la moneda como elemento amortizado en el tiempo, destinado finalmente a cumplir una función para la que no fue originalmente creada, convirtiéndose en un testigo de la presencia del donante en el santuario, equivalente, por consiguiente a la ofrenda de un vaso, una escultura o cualquier otro elemento. A todo lo anteriormente expuesto puede añadirse que la misma iconografía de dos de los ejemplares documentados puede potenciar su valor religioso en este contexto cultual, materializada en la asociación del toro y el creciente lunar a corrientes de agua, símbolos relacionados con la fecundidad (Olmos, 1992b).

\section{OTRAS OFRENDAS}

Otro conjunto de posibles ofrendas lo componen restos de elementos individualizados, muy particulares, de los que en la actualidad no se cuenta con un estudio detallado. Dentro de este grupo es necesario destacar la presencia de objetos personales como un alfiler en bronce o dos agujas de hierro de los que se desconoce si estuvieron asociados a la entrega de 
alguna prenda textil, tal y como se ha documentado en otros sitios arqueológicos de similares características (Izquierdo, 2001).

Dentro de este conjunto también se puede señalar la presencia de un pequeño recipiente de plata, con base plana, un alzado no superior a 1'7 $\mathrm{cm} \mathrm{y}$ borde ligeramente marcado. Sin duda un elemento ritual excepcional en el conjunto documentado en este santuario, que podría contener algún tipo de perfume o aceite y posiblemente destinado a participar en rituales de libación.

También es necesario indicar la aparición de pequeños fragmentos de vidrio que sin duda son restos de una botellita en este material, además de un cuenco en bronce en muy mal estado de conservación.

Un tema que sería necesario discutir en futuras investigaciones es la presencia de armas en los santuarios, entendidas como elementos de ofrenda. En el santuario de Las Atalayuelas se ha documentado, aunque descontextualizado por el proceso de expolio sufrido, una espada corta con la punta doblada de antiguo, probablemente inutilizada, que inicialmente podríamos identificar como una ofrenda, ya que en otros santuarios también han aparecido estos elementos interpretados como votivos en este contexto, así en Collado de los Jardines, La Cueva de la Lobera, el Cerro de los Santos, el Cigarralejo o la Luz (Moneo, 2003).

\section{CONTEXTUALIZACIÓN DE LOS SANTUARIOS IBÉRICOS TARDÍOS. SIGLO II A.N.E.-I D.N.E.}

El Santuario de las Atalayuelas se configura como uno de los ejemplos mas claros de santuarios que funcionan en un momento de cambio y transformaciones políticas, sociales y culturales producidas con la llegada de Roma, lugar de culto donde interactúan el factor colonizador y la «resistencia» indígena, siendo este segundo elemento el que prevalece en el conjunto, tal y como muestran las ofrendas que son fundamentalmente ibéricas, las esculturas de manufactura indígena, los vasos, etc. No obstante, como se ha señalado anteriormente, aparecen elementos novedosos, claramente romanos, fundamentalmente aquellos relacionados con aspectos vinculados a la propia estructura edilicia del santuario.

El santuario ha sido parcialmente excavado, por lo que aún no pueden analizarse aquellos aspectos relacionados con su distribución espacial o estructural. Sin embargo, la información obtenida puede enriquecerse con la aportada por la intervención realizada en el santuario de Torreparedones, cuya estructura ha sido identificada como perteneciente a un esquema oriental, de herencia fenicio-púnica (Fernández Castro y Cunliffe, 2002), con una división del edificio en tres partes: corredor, patio y cella (Ramallo, 1997; Brotons et al., 1994).

En cambio, la investigación realizada permite avanzar en otros aspectos, tales como su lectura en el marco geográfico concreto, local, del santuario, en el contexto del oppidum de Las Atalayuelas.

El santuario de Las Atalayuelas ha sido definido como «periurbano», por localizarse fuera de los límites marcados por la fortificación del oppidum, aunque dentro de su entorno inmediato, controlado desde el punto de vista político y económico, al igual que simbólico. Un entorno que puede suponerse antropizado, correspondiente al espacio más próximo a la ciudad, caracterizado por su carácter abierto, accesible, y no restringido.

Quizás sea éste el primer aspecto destacable en cuanto a que subraya el cambio con una etapa previa en la que la aristocracia ibérica controlaba y restringía el culto a sus antepasados como principal medio de legitimación de su poder. A partir del siglo III a.n.e. los indicadores arqueológicos muestran determinados cambios, como la ampliación de la base social del culto, tal y como se desprende del análisis iconográfico de los exvotos de bronce ibéricos procedentes de Despeñaperros y Castellar (Nicolini, 1969/1979; Prados, 1992).

La intervención realizada en Las Atalayuelas ha permitido la documentación de un lugar único, un depósito de ofrendas, caracterizado por la disposición de cientos de vasos apilados en un espacio restringido en el que también se localizan los exvotos de piedra y hierro y el resto de materiales identificados como ofrendas rituales. Este depósito votivo es, por tanto, muy heterogéneo, pero dentro de su variedad pueden observarse distintas categorías que se repiten hasta la saciedad, como es el caso de los cuencos de cerámica. Por otro lado existe un conjunto de elementos aislados, individualizados, tales como ajuares personales (alfileres de bronce, monedas, agujas de hierro,...) Ambos extremos indican que la comunidad representada e identificada con el santuario tiene una base social amplia, hecho que puede ser interrelacionado con el proceso de ampliación del culto iniciado en el siglo III a.n.e., pero también con los procesos de cambio social provocados por la conquista romana.

Esta idea es apoyada desde el punto de vista iconográfico, puesto que la mayor parte de las esculturas documentadas se caracteriza por manifestar una misma temática, la representación figurativa, destacando en las placas las imágenes de rostros en los que se enfatizan los ojos. En cambio, es inútil la 


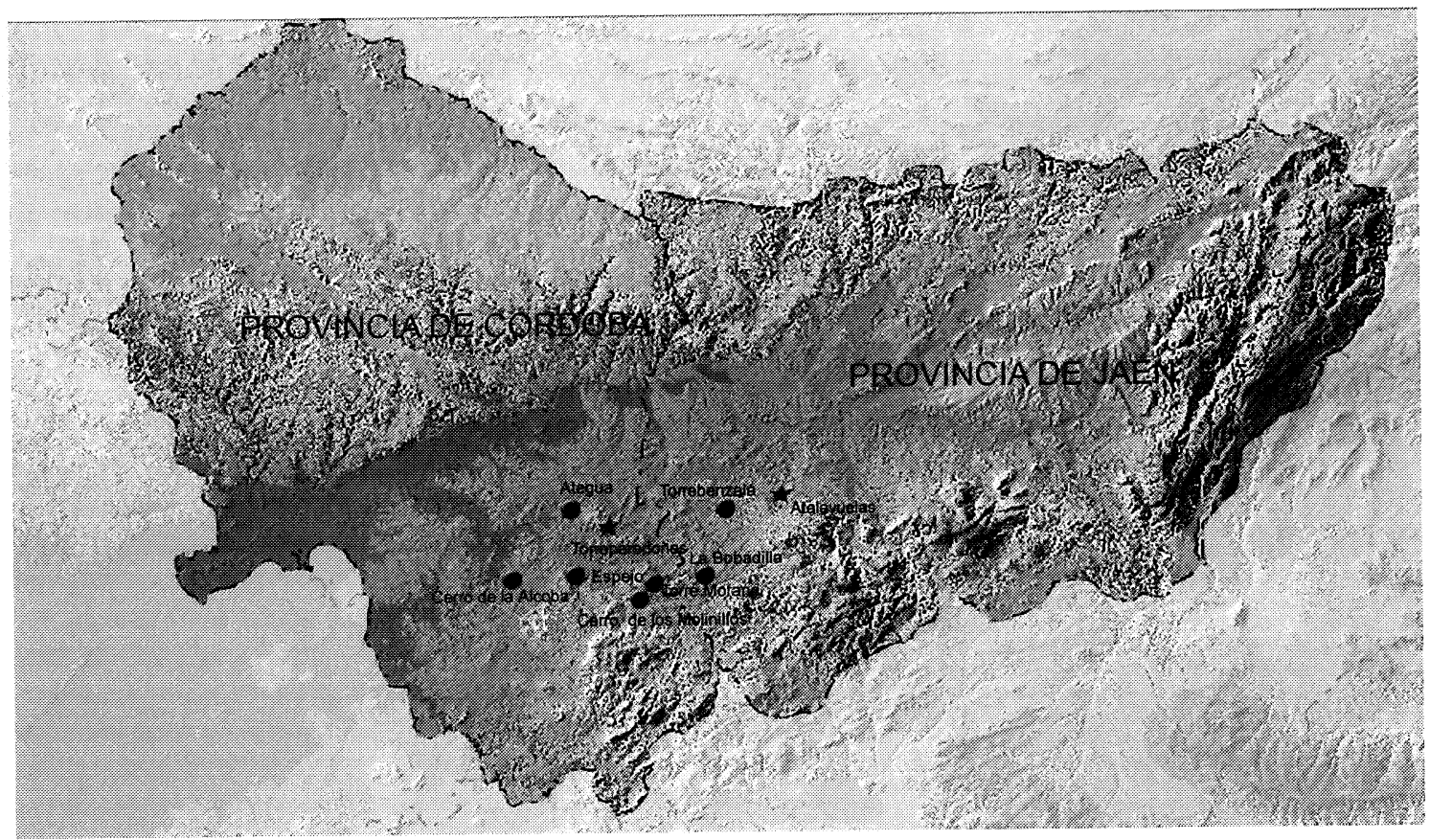

Fig. 14. Hipótesis de distribución de santuarios ibero-romanos en las provincias de Jaén y Córdoba.

búsqueda de elementos iconológicos característicos de una clase social aristocrática, como elementos de adorno en las figuras masculinas o la tira cruzada bajo el cuello, todos ellos antiguos símbolos de prestigio (Aranegui, 1996).

El santuario de Las Atalayuelas es quizás el reflejo de un primer intento de aproximación del culto a la ciudad, culto que tiende a legitimarla como nueva base de la identificación de la comunidad. Muy probablemente forme parte de un proyecto político trazado bajo parámetros romanos, en una fase de transición hacia modelos de culto netamente ciudadanos.

Frente a los modelos de culto desarrollados en los santuarios de Collado de los Jardines, La Encarnación, el Cigarralejo o el Cerro del los Santos, santuarios que muestran un proceso de monumentalización de sus anteriores estructuras (Ramallo, 1993; Ramallo et al., 1998) y que demuestran una línea político-ideológica basada en el reforzamiento y apropiación (quizás sincrética) de los cultos realizados en los mismos, en las campiñas de Jaén y Córdoba puede observarse un modelo peculiar, basado en la creación de santuarios periurbanos, que realmente no evidencian una ruptura, por parte de Roma, con los modelos indígenas anteriores, sino que parece materializarse en el intento de control y apropiación de determinados ritos que se mantendrían bajo parámetros ibéricos. Estos lugares de cul- to pueden relacionarse con la pervivencia de núcleos indígenas tras el primer impacto romanizador en las campiñas jienense y cordobesa, en un área muy determinada al sur del Guadalquivir, cuyos exponentes más significativos son Torreparedones y Atalayuelas, aunque existen numerosas evidencias materiales que estilísticamente pueden fecharse en esta etapa y corresponderse con centros de culto análogos a los excavados (fig. 14). Todos estos santuarios no distan mucho entre sí y pueden interpretarse como espacios de culto locales que siguen parámetros cultuales comunes que tienen su particular expresión en los exvotos en piedra con similares características técnicas, formales, iconológicas y simbólicas.

\section{BIBLIOGRAFÍA}

ALCALÁ VENCESLADA, A., 1930: Un relieve ibérico. Don Lope de Sosa, XVIII, Agosto, $\mathrm{n}^{\circ}$ 112, Jaén, 240-242.

ÁLVAREZ OSORIO, F., 1941: Catálogo de los exvotos de bronce ibéricos del Museo Arqueológico Nacional. 2 Vol. Madrid.

ARANEGUI, C., 1996: Signos de rango en la sociedad ibérica. Distintivos de carácter civil o religioso. Revista de Estudios Ibéricos 2, Madrid, 91-121.

BLÁZQUEZ, J.M.; MARTÍNEZ-PINNA, J. y MON- 
TERO, S., 1993: Historia de las religiones antiguas. Oriente, Grecia y Roma. Cátedra. Madrid.

BLECH, M., 1989: Republikanische Bronzestatuetten aus Sagunt. Homenaje a A. Chabret 18881998. Valencia, 45-91.

BROTONS, F. y RAMALLO, S., 1994: Un santuario suburbano: La Encarnación de Caravaca (Murcia),. XIV Actas del Congreso Internacional de Arqueología Clásica: La ciudad en el mundo romano. Vol. II. Tarragona, 74-75.

CASTRO, M., Inéd.: La Campiña de Jaén (ss. I-II dne). Construcción de un paisaje agrario. Tesis Doctoral inédita. Universidad de Jaén. Jaén. 1998.

CASTRO, M.; LÓPEZ, J.; ZAFRA, N.; CRESPO, J.M.; CHOCLÁN, C., 1990: Prospección con sondeo estratigráfico en el yacimiento de Atalayuelas, Fuerte del Rey (Jaén). Anuario Arqueológico de Andalucía de 1987. Volumen II. Actuaciones sistemáticas. Sevilla, 207-215.

CAZABÁN, A., 1920: En Fuerte del Rey: Buscando curiosidades arqueológicas. Revista Don Lope de Sosa. Jaén, 342-348.

CERRILLO, E., 1990: Arqueología de las religiones primitivas y arqueología de las religiones organizadas, Zephyrus $\mathrm{n}^{\circ}$ 43. Salamanca, 189-192.

COBOS, J. y LUQUE, F., 1990: Exvotos de Córdoba. Córdoba.

FERNÁNDEZ CASTRO, M.C. y CUNLIFFE, B.W., 2002: El yacimiento y el santuario de Torreparedones. Un lugar arqueológico preferente en la Campiña de Córdoba. BAR Internacional Series 1030. Oxford.

GARCÍA-BELLIDO, M.P., 1982: Las monedas de Cástulo con escritura indígena. Historia numismática de una ciudad minera. Universidad de Salamanca/ANE. Madrid.

GARCÍA-BELLIDO, M.P. y BLÁZQUEZ, C., 2001: Diccionario de cecas y pueblos hispáni$\cos$, (2 vol.). Consejo Superior de Investigaciones Científicas, Madrid.

GONZÁLEZ, M., 2002: Monedas romanas del Bajo Imperio procedentes del yacimiento ibérico de Collado de los Jardines en Santa Elena (Jaén). Actas del X Congreso Nacional de Numismática. Madrid, 431-438.

IZQUIERDO, I., 2001: La trama del tejido y el vestido femenino en la cultura ibérica. Tejer y vestir: de la antigüedad al Islam. Estudios Árabes e Islámicos: Monografías, 1. Manuela Marín, Ed. CSIC, Madrid. 287-314.

IZQUIERDO, I., 2003: La ofrenda sagrada del vaso en la cultura ibérica. Zephyrus, $n^{\circ} 56,117-135$.

MOLINOS, M.; CHAPA, T.; RUIZ, A.; PEREIRA,
J.; RISQUEZ, C.; MADRIGAL, A.; ESTEBAN, A.; MAYORAL, V.; LLORENTE, M.., 1998: El santuario heroico de «El Pajarillo» Huelma (Jaén). Universidad de Jaén. Jaén.

MONEO, T., 2003: Religio iberica: santuarios, ritos y divinidades (siglos VII-I a.C.). Bibliotheca Archaeologica Hispana, 20. Real Academia de la Historia. Madrid.

MORENA J.A., 1989 EL Santuario Ibérico de Torreparedones (Castro del Río, Baena, Córdoba). Córdoba, Ed. Excma. Diputación Provincial de Córdoba, Iltmo. Ayuntamiento de Baena, Iltmo. Ayuntamiento de Castro del Río.

MORENA, J.A., 1997: Los santuarios ibéricos en la provincia de Córdoba. Quaderns de Prehistòria $i$ Arqueologia de Castelló 18: "Espacios y lugares cultuales en el mundo ibérico». Castellón, 269298.

MORENA, J.A., 1999: A propósito de un particular tipo iconográfico de escultura votiva en piedra. Las figuras sedentes: ¿Divinidades, damas de alto rango o simples exvotos?. Anales de Arqueología Cordobesa 10, 9-23.

MOZAS MORENO, M.S., Ined.: Moneda hispánica en el Museo Provincial de Jaén. Memoria de Iniciación a la Investigación. Universidad de Jaén. Jaén. 2001.

NICOLINI, G., 1969: Les bronces figurés des sanctuaires ibériques. Bibliothèque de l'Ecole des Hautes Etudes Hispaniques 41. Paris.

NICOLINI, G., 1977 : Bronces Ibéricos. Traducción E. Guarro. Gustavo Gili. Barcelona.

NICOLINI, G.; RIZQUEZ, C.; RUIZ, A.; ZAFRA, N., 2004 : El Santuario ibérico de Castellar. Jaén. Intervenciones arqueológicas 1966-1991. Arqueología Monografías. Junta de Andalucía. Sevilla.

OLMOS, R., 1992a: Religiosidad e ideología ibérica en el marco del Mediterráneo. Notas preliminares sobre la antropomorfización de la imagen ibérica. Religiosidad y vida cotidiana en la España Ibérica. Seminarios Fons Mellaria, Vaquerizo (Coord.). 1991, 11- 45.

OLMOS, R., 1992b: La sociedad ibérica a través de la imagen. Catálogo de la exposición. Centro Nacional de Exposiciones. Ministerio de Cultura. Dirección General de Bellas Artes y Archivos. Madrid.

OLMOS, R., (Coord..), 1999: Los iberos y sus imágenes. CD-Room. Micronet, S.A. Madrid.

PRADOS, L., 1992: Exvotos ibéricos de bronce del Museo Arqueológico Nacional. Ministerio de Cultura. Madrid.

RAMALLO, S., 1993: La monumentalización de los 
santuarios ibéricos de época tardo-republicana. Ostraka. Rivista di Antichità II, Junio, 117-144.

RAMALLO, S., 1997: Templos y Santuarios en la Hispania Republicana. En Hispania Romana. Desde tierra de conquista a provincia del Imperio. J. Arce et al. Ed. Electa, 253-266.

RAMALLO, S.; NOGUERA, J.M.; BROTONS, F., 1998: El Cerro de los Santos y la monumentalización de los santuarios ibéricos tardíos. Revista de Estudios Ibéricos 3. Madrid, 11-69.

RIPOLLÉS , P.P. y ABASCAL, J.M., 2000: Monedas hispánicas. Real Academia de la Historia. Madrid.

RUANO, E., 1982-3: Aproximación a un catálogo de escultura ibérica en la provincia de Jaén. Cuadernos de Prehistoria y Arqueología de la Universidad Autónoma, 9-10. Madrid, 61-106.

RUANO, E., 1987: La escultura humana en piedra en el mundo ibérico. 3 Vol. Madrid.

RUEDA, C., Inéd.: Microprospección e historiografía para una nueva propuesta del proceso histórico de Collado de los Jardines (Santa Elena,
Jaén). Memoria de Licenciatura inédita. Universidad de Jaén. Jaén. 2002.

RUIZ BREMON, M., 1989: Los exvotos del santuario ibérico del Cerro de los Santos. Instituto de Estudios Albacetenses de la Excma. Diputación de Albacete. Albacete.

RUIZ, A., 1983: La ideología religiosa como aparato ideológico del Estado en el sur de la Península Ibérica durante la Protohistoria. Actas del I Congreso de Historia de Andalucía. Córdoba, 209-216.

RUIZ, A. y MOLINOS, M.,1993: Los iberos. Análisis arqueológico de un proceso histórico. Crítica. Barcelona.

VAQUERIZO, D., 1997: «Testimonios de la religiosidad ibérica en el territorio de la provincia de Córdoba». Quaderns de Prehistòria i Arqueologia de Castelló 18: "Espacios y lugares cultuales en el mundo ibérico». Castellón, 297-328.

VAQUERIZO, D. ,1999: La cultura ibérica en Córdoba. Un ensayo de síntesis. Universidad de Córdoba y Obra social y cultural Cajasur. Córdoba. 